\title{
Impact Time Guidance Law Considering Autopilot Dynamics Based on Variable Coefficients Strategy for Maneuvering Target
}

\author{
Wei Shang, Jie Guo, Shengjing Tang, Yueyue Ma, and Yao Zhang \\ Key Laboratory of Dynamics and Control of Flight Vehicle, Ministry of Education, School of Aerospace Engineering, \\ Beijing Institute of Technology, Beijing 100081, China \\ Correspondence should be addressed to Jie Guo; southcross@yeah.net
}

Received 10 March 2015; Accepted 27 May 2015

Academic Editor: Andrzej Swierniak

Copyright (C) 2015 Wei Shang et al. This is an open access article distributed under the Creative Commons Attribution License, which permits unrestricted use, distribution, and reproduction in any medium, provided the original work is properly cited.

This paper investigates the terminal guidance problem for the missile intercepting a maneuvering target with impact time constraint. An impact time guidance law based on finite time convergence control theory is developed regarding the target motion as an unknown disturbance. To further improve the performance of the guidance law, an autopilot dynamics which is considered as a first-order lag is taken into consideration. In the proposed method, the coefficients change with the relative distance between missile and target. This variable coefficient strategy ensures that the missile impacts the target at the desired time with little final miss distance. Then it is proved that states of the guidance system converge to sliding mode in finite time under the proposed guidance law. Numerical simulations are presented to demonstrate the effectiveness of the impact time guidance law with autopilot dynamics (ITGAD).

\section{Introduction}

When missiles attack the target with defense system or strong maneuverability, an effective way is salvo attack. Salvo attack means that several missiles, launched from different platforms or a single platform consecutively, hit the target at the same time. Consequently, the impact time is particularly important for salvo attack.

To improve the effectiveness of the warfare system, the guidance law with impact time constraint has been developed [1]. Jeon et al. [2] combined the well-known PNG law and the feedback of the impact time error. They proposed an impact time control guidance law to hit a stationary target simultaneously at a desirable impact time. A flight vehicle's homing guidance problem has been solved by Lee et al. [3] with the consideration of both impact time and impact angle. Harl and Balakrishnan [4] adopted the second-order sliding mode control method and designed a guidance law concerning impact time and angle constraints. Similarly, Zhang et al. [5] derived a close-form guidance law with the same constraints on the basis of biased proportional navigation guidance (BPNG). Then, with the impact time control guidance law, some papers deliberated the multimissile attack strategy [68].

Furthermore, in practical applications, the autopilot lag of missile exerts bad influence on guidance precision. To deal with the problem, [9-12] considered the autopilot dynamics in the process of designing guidance laws, which can compensate for the effects of the autopilot dynamics. Moosapour et al. [13] proposed a novel robust proportional navigation guidance (RPNG) law by integrating sliding mode control and proportional navigation guidance law which assumed the autopilot dynamics as first-order lags system. Formulating a fourth-order state equation for integrated guidance and control loop with target uncertainties and control loop dynamics, Chwa and Choi [14] derived an adaptive nonlinear guidance law. Qu and Zhou [15] presented a dimension reduction observer-based guidance law based on the dynamic surface control-method regarding the missile autopilot as second-order dynamics. Taking both the autopilot dynamics and uncertainties into consideration, Li et al. [16] developed a finite time convergent guidance law for homing missile to intercept a maneuvering target. 
To the best of our knowledge, we find that the existing impact time control guidance laws are mainly for hitting the stationary or weak maneuverability target. Based on this observation, we proposed an impact time guidance law for attacking a maneuvering target, in which the impact time and the light-of-sight (LOS) angular rate are chosen as the sliding variables while the motion of target is taken as disturbance. In addition, the existing impact time control guidance laws do not concern the dynamics of the autopilot. To further improve the effectiveness of our proposed method, the autopilot regarded as first-order dynamics is taken into account based on the finite time convergence theory. To ensure that the missile impacts the target at desired time, a strategy making the coefficient vary with relative distance which can be easily measured by a missile guided seeker is designed in the guidance law. Then, an impact time guidance law considering autopilot dynamics based on variable coefficients strategy (ITGAD) is derived.

Compared with the previous works on impact time control, the advantages of ITGAD are that, first, it deals with the problem of missiles impacting a maneuvering target at the desired impact time. Then ITGAD considered the autopilot dynamics which may induce time lags during the terminal guidance process. The remainder of this paper is organized as follows. Section 2 describes the relative motion models for missile and target. In Section 3, an impact time guidance law considering autopilot dynamics is derived. Variable coefficient strategy is proposed and the stability of the guidance system is verified in Section 4. Finally, simulation results and analysis of the guidance law are provided.

\section{Equations of Motion}

This section formulates the mathematic model of the guidance system for intercepting. The planar relative motion of missile and target is shown in Figure 1, where the missile and the target are denoted by subscripts $M$ and $T$, respectively. In this scenario, the missile is traveling at a constant velocity. To simplify the guidance law design, missile and target are assumed to be point masses, and only kinematics is considered. The corresponding equations of guidance are given by

$$
\begin{aligned}
\dot{r} & =-v_{M} \cos \sigma_{M}+v_{T} \cos \sigma_{T}, \\
r \dot{q} & =v_{M} \sin \sigma_{M}-v_{T} \sin \sigma_{T}, \\
\sigma_{M} & =q-\theta_{M}, \\
\sigma_{T} & =q-\theta_{T}, \\
\dot{\theta}_{M} & =\frac{a_{M}}{v_{M}}, \\
\dot{\theta}_{T} & =\frac{a_{T}}{v_{T}},
\end{aligned}
$$

where $r$ is the relative distance, $\dot{r}$ is the relative velocity of the missile and the target, $v_{M}$ is the missile velocity, $a_{M}$ denotes the missile lateral acceleration which is normal to missile velocity, and $\theta_{M}$ represents the missile flight-path angle. $v_{T}$ is

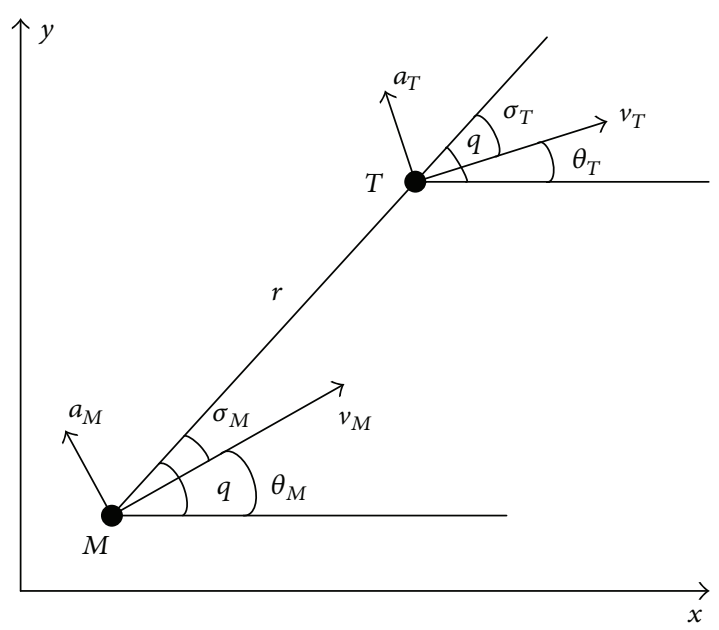

FIGURE 1: Relative motion of missile and target.

the target velocity, $a_{T}$ is the target lateral acceleration that is normal to target velocity, $\theta_{T}$ is the target flight-path angle, and $q$ and $\dot{q}$ are the light-of-sight (LOS) angle and LOS angular rate of missile and target, respectively.

To simplify the transformation from the missile dynamics, we assume that the velocities of the missile and the target are constant. Then differentiating (1) and (2) with respect to time yields

$$
\begin{aligned}
& \dot{V}_{R}=\frac{V_{R}^{2}}{r}+a_{T R}-a_{M} \sin \sigma_{M}, \\
& \dot{V}_{q}=\frac{V_{q} V_{R}}{r}-a_{T q}+a_{M} \cos \sigma_{M},
\end{aligned}
$$

where $V_{R}=\dot{r}, V_{q}=r \dot{q}, a_{T R}=a_{T} \cos \sigma_{T}$, and $a_{T q}=a_{T} \sin \sigma_{T}$. $a_{T R}$ and $a_{T q}$ are the target's tangential acceleration and normal acceleration, respectively.

A useful variable when analyzing a homing guidance is the time-to-go, $t_{\mathrm{go}}$, which indicates the time required for the missile to hit the target on its present course. In this work, the time-to-go parameter is approximated as

$$
t_{\mathrm{go}}=\frac{r}{|\dot{r}|} \text {. }
$$

In the terminal guidance process, usually only the acceleration normal to missile's velocity can be adjusted and so we will just discuss the relative motion normal to the LOS while $\dot{r}<0$. Equation (9) can be written as

$$
t_{\mathrm{go}}=-\frac{r}{\dot{r}} \text {. }
$$

To make the LOS angular rate converge to zero in finite time, define two state variables as

$$
\begin{aligned}
& x_{1}=\dot{q}, \\
& x_{2}=t_{\mathrm{go}} .
\end{aligned}
$$

From (8), we can obtain

$$
\dot{x}_{1}=-\frac{2 V_{R}}{r} x_{1}-\frac{a_{M} \cos \sigma_{M}}{r}+\frac{a_{T q}}{r} .
$$


Differentiating (1) and (10) with respect to time, we immediately get

$$
\dot{x}_{2}=-1-\frac{r V_{q}}{V_{R}^{2}} x_{1}-\frac{a_{M} r \sin \sigma_{M}}{V_{R}^{2}}+\frac{r a_{T R}}{V_{R}^{2}} .
$$

The design objective here is to develop a guidance law. This guidance law not only can ensure the missile has a short miss distance, but can intercept the maneuvering target at the desired impact time. That is, we develop a guidance law such that the LOS angular rate $\dot{q}$ will converge to zero and the impact time $t_{\text {go }}$ will converge to the value of $t_{d}-t$ in finite time in the presence of maneuvering targets.

\section{Finite Time Convergence Guidance Law with Impact Time and Autopilot Dynamics}

3.1. Finite Time Convergence System. For designing the finite time convergence guidance law, we make a definition on the finite time stability of SISO system and a lemma first.

Definition 1 (see [17]). Consider a SISO system:

$$
\dot{x}(t)=f(t)+g(t) u+\omega, \quad x \in \Omega,
$$

where $x(t)$ is the state variables of the system, $u$ is a smooth control input, $f(t)$ and $g(t)$ are known functions, and $\omega$ is smooth disturbance of system. The function is interpreted as the sliding variable dynamics. For any given initial time $t_{0}$ and initial state $x_{0}$, there will exist a settling time $T \geq 0$ so that the every solution of the system satisfies

$$
\begin{gathered}
\lim _{t \rightarrow T} x(t)=0, \quad t \in\left[t_{0}, T\right], \\
x(t)=0, \quad t>T .
\end{gathered}
$$

When the system is Lyapunov stable with finite time convergence, then the system is called finite time stable.

Lemma 2 (see [18]). Consider the nonlinear system described by (14). Suppose there exists an open neighborhood $\Theta$ of the origin, a $C^{1}$ positive-definite function $V: \Theta \rightarrow \Omega$, and real numbers $\alpha>0$, such that $\dot{V}+\alpha V^{\kappa}$ is negative semidefinite on $\Theta$. Then the origin is a finite time stable equilibrium of (14). Moreover, if $T$ is the settling time, then $T \leq(1 / \alpha(1-\kappa)) V^{1-\kappa}$ for all $x$ in some open neighborhood of the origin.

3.2. Impact Time Guidance Law Based on Finite Time Convergence Control with Integral Manifold. Considering the process of the terminal guidance of missile, the following sliding mode manifold is introduced:

$$
\begin{aligned}
& s_{1}=s_{2}+\xi, \\
& s_{2}=x_{1}+\frac{k_{1} v_{M}}{r} s_{3}, \\
& \dot{\xi}=k_{2}\left|x_{1}\right|^{1 / 2} \operatorname{sgn} x_{1}+k_{3}\left|s_{3}\right|^{1 / 2} \operatorname{sgn} s_{3}, \\
& s_{3}=x_{2}-\left(t_{d}-t\right),
\end{aligned}
$$

where $k_{1}, k_{2}, k_{3}$ are positive constants and $t_{d}$ is the desired impact time. The initial value is denoted as $s_{2}(0)=x_{1}(0)+$ $\left(k_{1} v_{M} / r(0)\right) s_{3}(0)$ and $s_{3}(0)=x_{2}(0)-t_{d}$ which mean the LOS angular rate error $\dot{q}$ and impact time error $x_{2}-\left(t_{d}-t\right)$ on the sliding mode manifold starting from the initial time instance.

Theorem 3. Consider the guidance system (1) (6) and (10) (11). In the following time convergence guidance law:

$$
a_{M}=\frac{-2 V_{R} x_{2}-k_{1} v_{M} V_{R} s_{3} / r-k_{1} r x_{2} V_{q} / V_{R}^{2}+\left(\beta\left|s_{1}\right|^{\eta_{1}}+\phi / r\right) \operatorname{sgn} s_{1}+k_{2}\left|x_{1}\right|^{1 / 2} \operatorname{sgn} x_{1}+k_{3}\left|s_{3}\right|^{1 / 2} \operatorname{sgn} s_{3}}{\cos \left(\theta_{M}-q\right)-k_{1} r v_{M} \sin \left(\theta_{M}-q\right) / V_{R}^{2}},
$$

the switching term amplitude $\beta$ satisfies $\beta>0$ and $\phi$ satisfies $\phi>\max (\omega) r$, where $\omega$ is target motion which is considered as disturbance of the guidance system. Then, the guidance law (20) guarantees that the LOS angular rate $\dot{q}$ converges to zero and the impact time $t_{g o}$ converges to the value of $t_{d}-t$ in finite time.

Proof. Differentiating (16), (17), and (19) with respect to time yields

$$
\begin{aligned}
\dot{s}_{1}= & \dot{x}_{1}-\frac{k_{1} v_{M} \dot{r}}{r^{2}} s_{3}+\frac{k_{1} v_{M}}{r}\left(\dot{x}_{2}+1\right) \\
& +k_{2}\left|x_{1}\right|^{1 / 2} \operatorname{sgn} x_{1}+k_{3}\left|s_{3}\right|^{1 / 2} \operatorname{sgn} s_{3} .
\end{aligned}
$$

Substituting (12) and (13) into (21) and with (20),

$$
\begin{aligned}
\dot{s}_{1}= & -\frac{2 V_{R}}{r} x_{1}-\frac{a_{M} \cos \sigma_{M}}{r}+\frac{a_{T q}}{r}-\frac{k_{1} v_{M} \dot{r}}{r^{2}} s_{3} \\
& +\frac{k_{1} v_{M}}{r}\left(-\frac{r V_{q}}{V_{R}^{2}} x_{1}-\frac{a_{M} r \sin \sigma_{M}}{V_{R}^{2}}+\frac{r a_{T R}}{V_{R}^{2}}\right) \\
= & -\left(\beta\left|s_{1}\right|^{\eta_{1}}+\frac{\phi}{r}\right) \operatorname{sgn} s_{1}+\omega,
\end{aligned}
$$

where $\omega=a_{T q} / r+k_{1} v_{M} a_{T R} / V_{R}^{2}$ is denoted as target motion. Define a Lyapunov function

$$
V_{1}=\frac{1}{2} s_{1}^{2}
$$


The derivative of $V_{1}$ along the trajectories of (22) satisfies

$$
\begin{aligned}
\dot{V}_{1} & \leq-\beta\left|s_{1}\right|^{\eta_{1}+1}-\left(\frac{\phi}{r}\left|s_{1}\right|-\omega\left|s_{1}\right|\right) \leq-\beta\left|s_{1}\right|^{\eta_{1}+1} \\
& =-\beta V_{1}^{\left(\eta_{1}+1\right) / 2} \leq 0 .
\end{aligned}
$$

This implies that $V_{1}(t) \leq V_{1}(0)$. Now, by Lemma 2, the LOS angular rate converges to zero and the impact time converges to the value of $t_{d}-t$ in finite time, and the settling time is given by

$$
T \leq \frac{2}{\beta\left(1-\eta_{1}\right)} V_{1}^{\left(1-\eta_{1}\right) / 2} \leq \frac{2}{\beta\left(1-\eta_{1}\right)} V_{1}(0)^{\left(1-\eta_{1}\right) / 2} .
$$

The proof is finished.

3.3. Impact Guidance Law with Autopilot Dynamics. The acceleration command generated by the guidance law is achieved by a missile's autopilot which tracks the expected acceleration command by modulating fins or thrusters. There is a lag between the expected acceleration and the achieved acceleration. The lag will induce bad influence on the guidance law, especially with the time limited. In practical application, designing the guidance law considering autopilot dynamics is the best way to improve the performance of the missile. The autopilot can be well approximated as the following first-order dynamics:

$$
\dot{a}_{M}=-\frac{1}{T_{1}} a_{M}+\frac{1}{T_{1}} u,
$$

where $a_{M}$ is the actual acceleration command, $T_{1}$ is the time constant of the autopilot, and $u$ is the missile acceleration command.

The acceleration command $u$ is easy to be obtained, if the actual acceleration command $a_{M}$ and its differential form $\dot{a}_{M}$ can be known. However, the differential form of actual acceleration command includes the first-order derivative of the LOS angular rate which is hard to be accurately estimated, thus making it impossible to implement the guidance law. Thus, low-pass filter is adopted to solve this problem. follows:

Pass guidance law (20) through a first-order filter as

$$
\frac{\widehat{a}_{M}}{a_{M}^{*}}=\frac{1}{\tau s+1}, \quad a_{M}^{*}(0)=\widehat{a}_{M}(0),
$$

where $a_{M}^{*}$ is a control law obtained from (20), $\widehat{a}_{M}$ is the output of first-order filter, and $\tau$ is a time constant.

Considering the autopilot dynamics and the first-order filter, the following sliding mode manifold and the resolution error of the first-order filter are introduced:

$$
\begin{gathered}
s_{4}=a_{M}-\widehat{a}_{M}, \\
y=a_{M}^{*}-\widehat{a}_{M} .
\end{gathered}
$$

Theorem 4. Consider (20), (26), and (27). In the following control law:

$$
u=a_{M}+\frac{T_{1}}{\tau} y-T_{1} v_{M} \varepsilon \operatorname{sgn} s_{4}
$$

the time constant $\tau$ satisfies $\tau \leq|y| /\left(\left|\dot{a}_{M}^{*}\right|+C\right),|\varepsilon|=C$, and $\varepsilon<0$, where $C$ is a positive constant. The control law ensures that the lag between the expected acceleration and the achieved acceleration converges to zero in finite time.

Proof. Differentiating (28) with respect to time yields gives

$$
\begin{aligned}
& \dot{s}_{4}=-\frac{1}{T_{1}} a_{M}+\frac{1}{T_{1}} u-\dot{\hat{a}}_{M}, \\
& \dot{y}=\dot{a}_{M}^{*}-\frac{1}{\tau} y .
\end{aligned}
$$

Define a Lyapunov function

$$
V_{2}=\frac{1}{2} s_{2}^{2}+\frac{1}{2} y^{2}
$$

With (29) and (30), the derivative of $V_{2}$ is deduced as

$$
\dot{V}_{2}=s_{2} \dot{s}_{2}+y \dot{y}=\varepsilon\left|s_{2}\right|+\dot{a}_{M}^{*} y-\frac{1}{\tau} y^{2} .
$$

The elements of guidance system are all bounded, so $\dot{a}_{M}^{*} \leq$ $\left|\dot{a}_{M \max }^{*}\right|$ is a nonnegative function and has a maximum value. With $\tau \leq|y| /\left(\left|\dot{a}_{M \max }^{*}\right|+C\right)$, (32) can be obtained as

$$
\dot{V}_{2} \leq \varepsilon\left|s_{2}\right|-C|y| \leq-4|\varepsilon| V_{2}^{1 / 2} \leq 0 .
$$

Since $|\varepsilon|>0$ and $V_{2}^{1 / 2}>0$ for $V_{1} \neq 0$, there is $\dot{V}_{1}(t)<0$. The system satisfies the Lyapunov stability. By Lemma 2, the expected acceleration converges to the achieved acceleration in finite time, and the settling time is given by

$$
T \leq \frac{1}{2|\varepsilon|} V_{1}^{1 / 2} \leq \frac{1}{2|\varepsilon|} V_{1}(0)^{1 / 2} .
$$

The ITGAD law involves a signum function which induces the chattering effect. So, to remove the chattering, it can be smoothened with a saturation function sat $(s)$. The saturation function is expressed as

$$
\operatorname{sat}(s)=\frac{s}{|s|+\delta}
$$

where $\delta$ is a small positive constant.

\section{Impact Time Guidance Law Based on Variable Coefficient Strategy}

To prove the stability of the guidance system, we need the following theorem.

Theorem 5. Consider the function $V=(1 / 2) s^{2}: \Psi \rightarrow$ $\Omega$, where $s\left(x_{1}, x_{2}, \ldots, x_{n}, k\right), x_{1}, x_{2}, \ldots, x_{n}$ is the states of this function and $k$ is a positive constant, the differential of the function $V$ is a negative semidefinite on $\Psi$, and the function sis finite time stable. Suppose there exists a continuous differentiable function $k(t)>0: t \in \Omega$; the function s is globally finite time stable for all $t$ in some open neighborhood of the origin. 
Proof. For $\Delta t_{i} \in \Omega$ and $\Delta t_{i} \rightarrow 0, k\left(\Delta t_{i}\right)$ is nearly a positive constant. Thus, it is clear that

$$
\dot{V}\left(k_{i}\right) \leq 0, \quad \forall \Delta t_{i} \in \Omega .
$$

In the area of $\Delta t_{i}, s$ is finite time stable. And there exists

$$
V_{t}\left(k_{i}\right) \leq V_{0}\left(k_{i}\right)
$$

where $V_{0}$ is the initial state and $V_{t}$ is the final state in the area of $\Delta t_{i}$.

In the area of $\Delta t_{i+1}$, there exists

$$
V_{t}\left(k_{i+1}\right) \leq V_{0}\left(k_{i+1}\right)=V_{t}\left(k_{i}\right)
$$

As the function $k(t)$ for $t \in \Omega, V_{t}(k) \leq V_{0}(k)$ and $V(k(t))<0$, where $V_{0}(k)$ is the initial state of the function.
Moreover, by Lemma 2, if $T$ is the settling time, $T$ can be written as

$$
\begin{aligned}
T & \leq \Delta t_{1}+\Delta t_{2}+\cdots+\Delta t_{l}+\frac{1}{\alpha(1-\kappa)} V_{0}\left(k_{l}\right)^{1-\kappa} \\
& <\Delta t_{1}+\Delta t_{2}+\cdots+\Delta t_{l}+\frac{1}{\alpha(1-\kappa)} V_{0}(k)^{1-\kappa}
\end{aligned}
$$

Equation (39) implies that the function is globally finite time stable. The proof is finished.

In the guidance law (20) and (29), $k_{1}, k_{2}$, and $k_{3}$ are selected mainly based on the desired time and initial states of missile. To avoid this problem, the variable strategy is proposed to achieve the objective that the missile impacts the target in the desired time. From the sliding mode manifold (16) (19), $k_{1}$ and $k_{3}$ are coefficients concerning impact time which determine the impact time of the missile and $k_{2}$ is coefficient concerning LOS angular rate which determines the final miss distance of the missile. The guidance law with variable strategy is given as

$$
\begin{aligned}
a_{M} & =\frac{-2 V_{R} x_{2}-k_{1}(r) v_{M} V_{R} s_{3} / r-k_{1}(r) r x_{2} V_{q} / V_{R}^{2}+\left(\beta\left|s_{1}\right|^{\eta_{1}}+\phi / r\right) \operatorname{sgn} s_{1}+k_{2}(r)\left|x_{1}\right|^{1 / 2} \operatorname{sgn} x_{1}+k_{3}(r)\left|s_{3}\right|^{1 / 2} \operatorname{sgn} s_{3}}{\cos \left(\theta_{M}-q\right)-k_{1} r v_{M} \sin \left(\theta_{M}-q\right) / V_{R}^{2}}, \\
u & =a_{M}+\frac{T_{1}}{\tau} y-T_{1} v_{M} \varepsilon \operatorname{sgn} s_{4},
\end{aligned}
$$

where $k_{1}(r), k_{2}(r)$, and $k_{3}(r)$ are functions with respect to the system parameters. The focus of this strategy is to adjust $k_{1}(r), k_{3}(r)$ to a small value and $k_{2}(r)$ to a large value when the missile is close to the target to ensure that the missile impacts the target with little final miss distance. As the relative distance between missile and target can be detected easily by the seekers, an available approach in this paper is to make the coefficients vary with the relative distance. The functions of $k_{1}(r), k_{2}(r)$, and $k_{3}(r)$ are defined as

$$
\begin{aligned}
& k_{1}(r)=k_{1}\left(\frac{r-r_{0} / \alpha}{\left|r-r_{0} / \alpha\right|+\delta_{k}}+1\right), \\
& k_{2}(r)=k_{2}\left(\frac{-r+r_{0} / \chi}{\left|-r+r_{0} / \chi\right|+\delta_{k}}\right)+k_{2}, \\
& k_{3}(r)=k_{3}\left(\frac{r-r_{0} / \eta}{\left|r-r_{0} / \eta\right|+\delta_{k}}+1\right),
\end{aligned}
$$

where $k_{1}, k_{2}$, and $k_{3}$ are positive constant. $r_{0}$ is the initial relative distance. $\alpha, \chi$, and $\eta$ are positive constants which determine whether the missile impacts the target in the desired time. $\delta_{k}$ is short durations for the variation of $k_{1}(r)$, $k_{2}(r)$, and $k_{3}(r)$.

Theorem 6. In the guidance law (40), the coefficients of (41) are positive constants. $\beta$ satisfies $\beta=|\varepsilon|$ and $\eta_{1}=0$. The guidance system with autopilot dynamics is globally finite time stable and the guidance law ensures that the LOS angular rate converges to zero and the rate of the impact time converges to the value of $t_{d}-t$ in finite time.

Proof. As $\delta_{k}>0, k_{1}>0, k_{2}>0$, and $k_{3}>0, k_{1}(r)>0$, $k_{2}(r)>0$, and $k_{3}(r)>0$ for all $r$ in the guidance law.

Choosing small clips of the guidance law, $k_{1}\left(\Delta r_{i}\right), k_{2}\left(\Delta r_{i}\right)$, and $k_{3}\left(\Delta r_{i}\right)$ are nearly a constant. Define a Lyapunov function

$$
V=V_{1}+V_{2}
$$

The derivative of $V$ is

$$
\dot{V}=\dot{V}_{1}+\dot{V}_{2} \leq-\beta V_{1}^{\left(\eta_{1}+1\right) / 2}-|\varepsilon| V_{2}^{1 / 2}=-2 \beta V^{1 / 2} .
$$

Since $\beta>0$ and $V^{1 / 2}>0$ for $V \neq 0$, there is $\dot{V}(t)<0$. The system satisfies the Lyapunov stability. By Lemma 2, the settling time is given by

$$
T_{i}=\frac{1}{\beta} V\left(\Delta r_{i}\right)^{1 / 2}<\frac{1}{\beta} V(0)^{1 / 2} .
$$

By Theorem 5, the settling time of the guidance system is

$$
T \leq \sum_{i=1}^{n} \Delta t_{i}+\frac{1}{\beta} V\left(\Delta r_{n-1}\right)^{1 / 2}<\sum_{i=1}^{n} \Delta t_{i}+\frac{1}{\beta} V(0)^{1 / 2},
$$

where $\Delta t_{i}$ is the time of $i$ th clip of the guidance law and set to be $\Delta t_{i}=\Delta r_{i} / \dot{r}_{i}$. Then the guidance system is globally finite time stable. The proof is finished. 


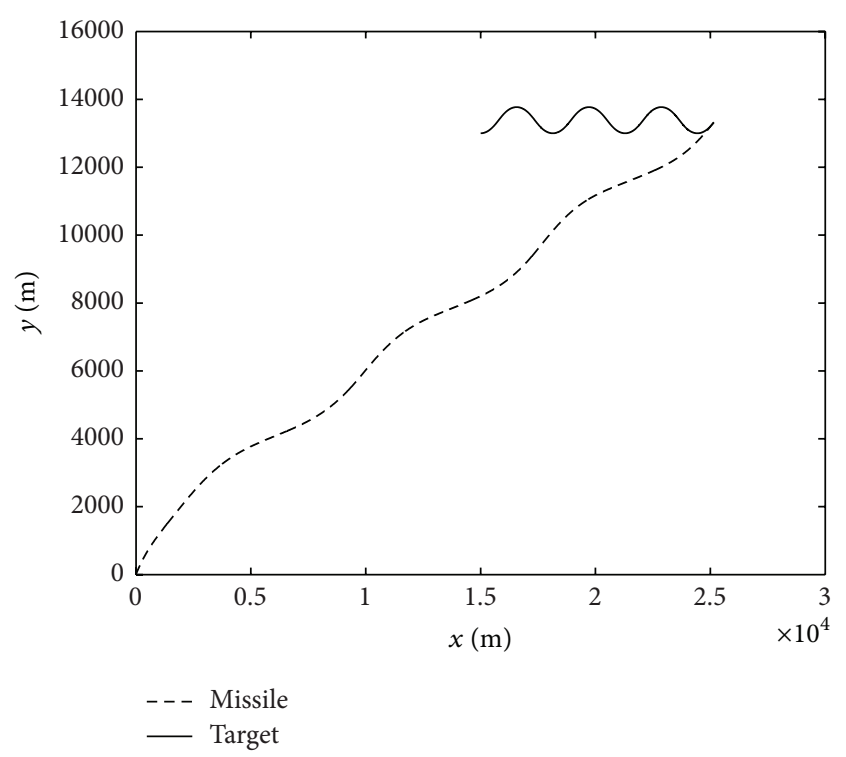

FIGURE 2: Trajectories of missile and target under FTCG.

\section{Simulation}

In this section, simulations of the proposed ITGAD guidance law are presented for a variety of scenarios. The missile's maximum acceleration is $80 \mathrm{~g}$, where $g$ is the gravity acceleration. The parameters of ITGAD are set to be $\beta=1, \eta_{1}=0$, $T_{1}=0.05, \varepsilon=-1, \tau=0.01$, and $\phi=300$. For each simulation, it is assumed that the desired time is chosen to be larger than the impact time based on finite time convergence guidance (FTCG) [17].

Case 1 (impact a maneuvering target with constant velocity). For comparison, we apply the proposed guidance laws ITGAD and FTCG in this simulation. The missile speed is $1000 \mathrm{~m} / \mathrm{s}$ with an initial heading angle of $60 \mathrm{deg}$. The target speed is $400 \mathrm{~m} / \mathrm{s}$ with an initial heading angle of 0 deg. target's normal acceleration is set to be $20 \mathrm{~g} \cos 0.7 \mathrm{t}$. The initial positions of the missile and target are taken as $(0,0) \mathrm{km}$ and $(15,13) \mathrm{km}$, respectively. Figures 2 and 3 show the trajectories and relative distance of missile and target under FTCG. The impact time is observed in simulation to be about $28.94 \mathrm{~s}$ as shown in Figure 3. The following simulation uses the same conditions, only now a designated impact time of $35 \mathrm{~s}$ is specified. The results of ITGAD are represented in Figures 48.

Figure 4 shows that the missile impacts the target at $34.95 \mathrm{~s}$ with the impact time error of $0.05 \mathrm{~s}$. Meanwhile, the trajectories of missile and target with $0.02823 \mathrm{~m}$ final miss distance are shown in Figures 5 and 9. To ensure that the missile impacts the target at desired impact time, the missile turns slightly away from the target. Because of the variable coefficient strategy, at the end of the terminal guidance, the missile requires a high maneuverability to guarantee that the impact time is equal to the desired impact time as shown in Figure 8. Figures 6 and 7 illustrate that, under the ITGAD,

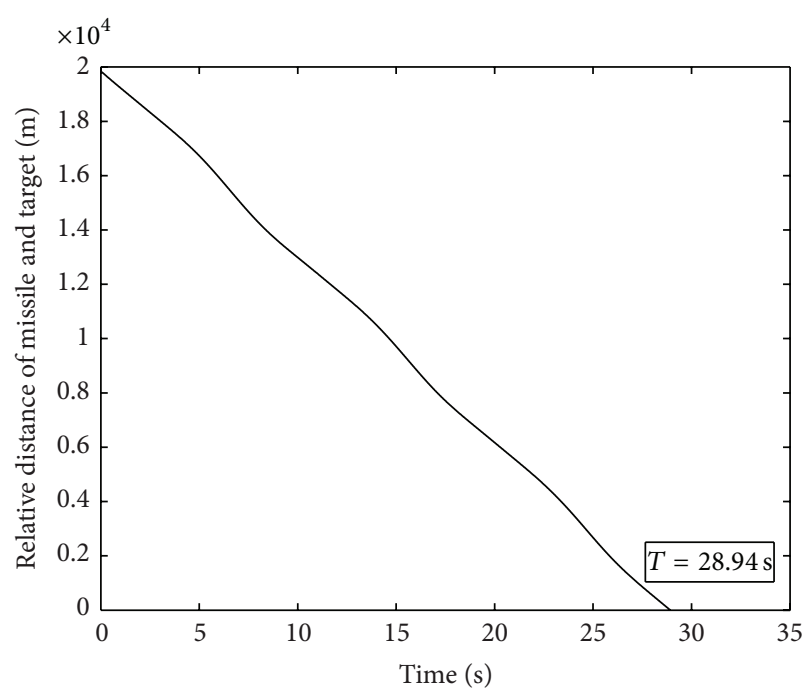

FIgURE 3: Relative distance of missile and target under FTCG.

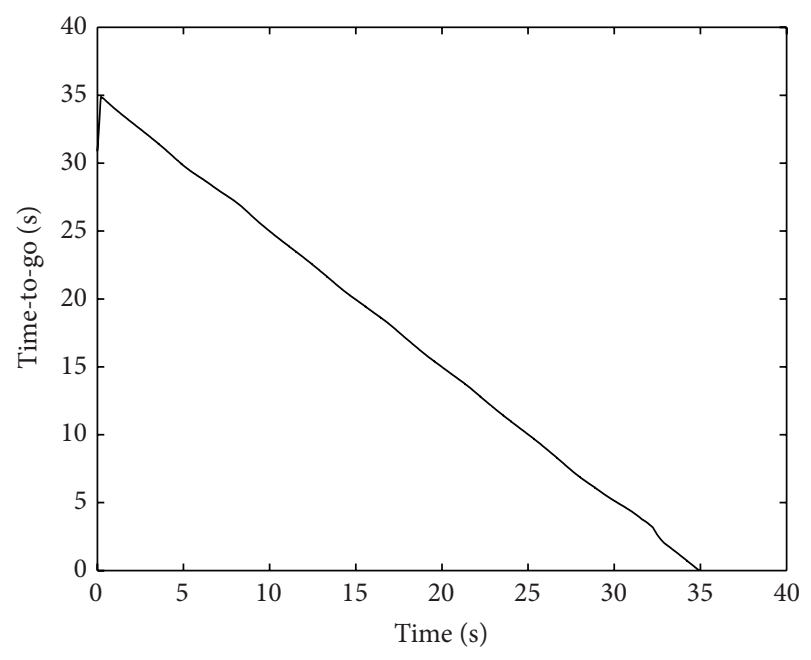

FIgURE 4: Time-to-go.

the LOS angular rate and the rate of time-to-go converge to a small neighborhood of sliding surface.

Case 2 (impact a maneuvering target with variable velocity). Different from Case 1, the velocity of target in this case is set to be varied. As $t<18 \mathrm{~s}$, the acceleration components of target's tangential acceleration are set to be $5 \mathrm{~m} / \mathrm{s}^{2}$. As $t \geq 18 \mathrm{~s}$, the tangential acceleration becomes $-15 \mathrm{~m} / \mathrm{s}^{2}$. The initial speed of target is $400 \mathrm{~m} / \mathrm{s}$ with an initial heading angle of $0 \mathrm{deg}$. The acceleration component of the target normal to the velocity is set to be $20 \mathrm{~g} \cos 0.7 t$. The remaining conditions are the same as Case 1. Figure 10 demonstrates the trajectories of missile and target under FTCG. Figure 11 shows the relative distance of missile and impact time of the terminal guidance process under FTCG. The designed impact time is $35 \mathrm{~s}$. Simulations under ITGAD are given in Figures 12-17. From Figures 12 

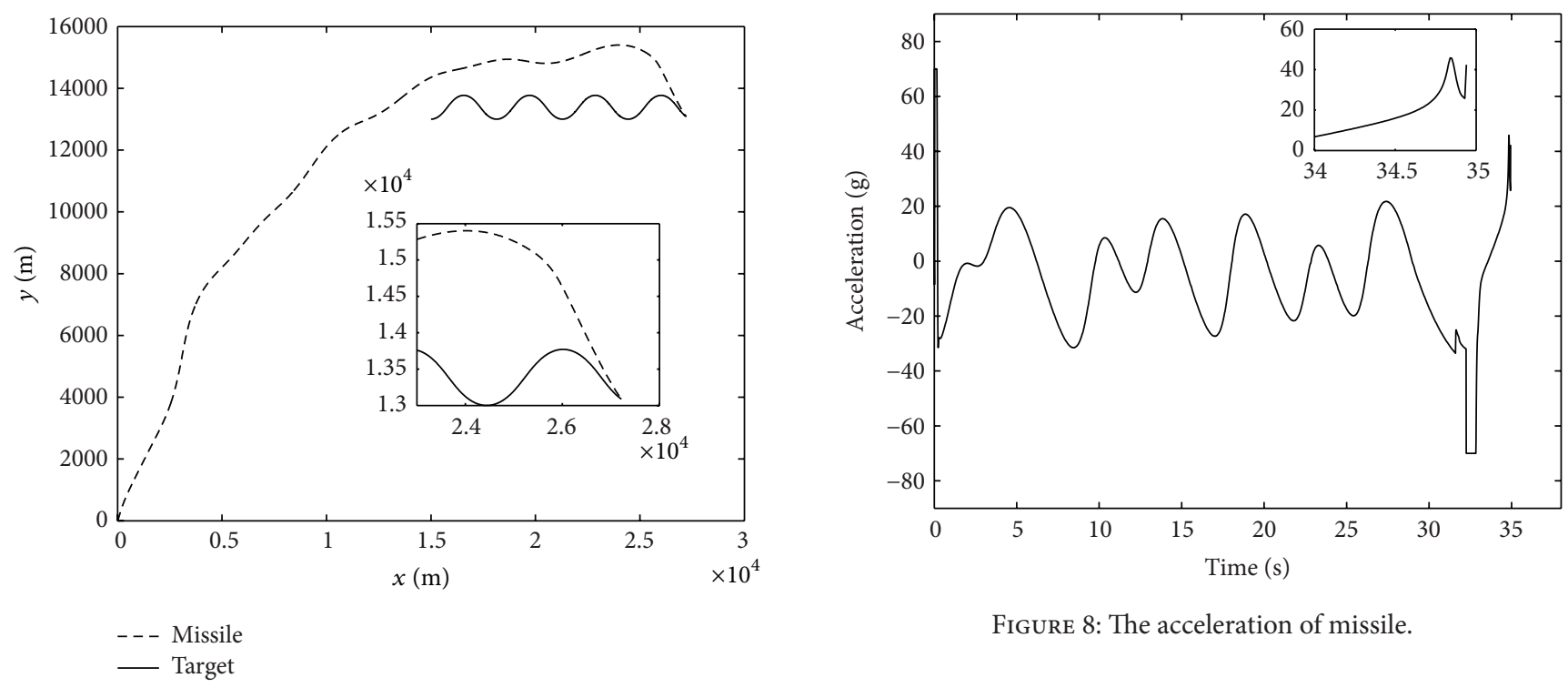

FIgURE 8: The acceleration of missile.

FiguRE 5: Trajectories of missile and target.

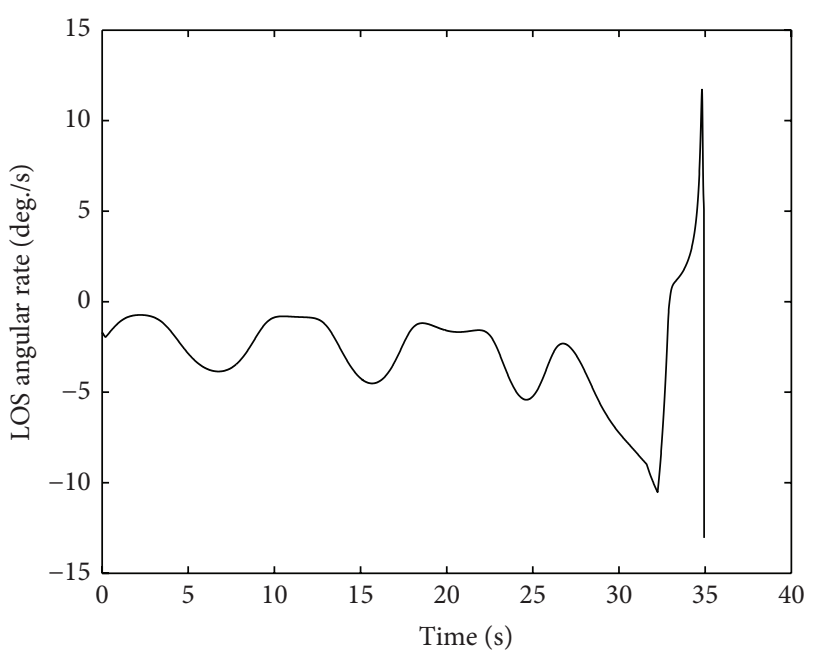

FIGURE 6: LOS angular rate.

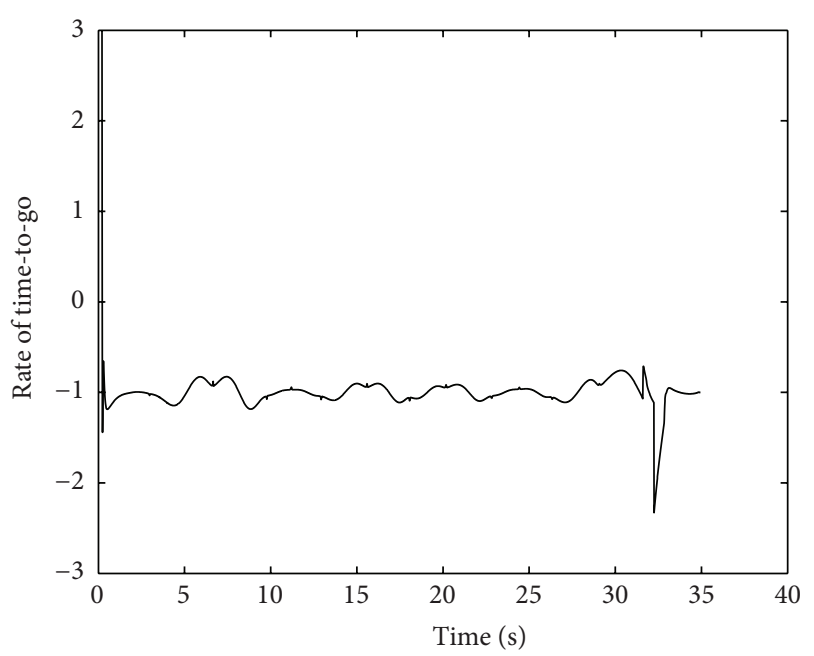

FiguRE 7: Rate of time-to-go.

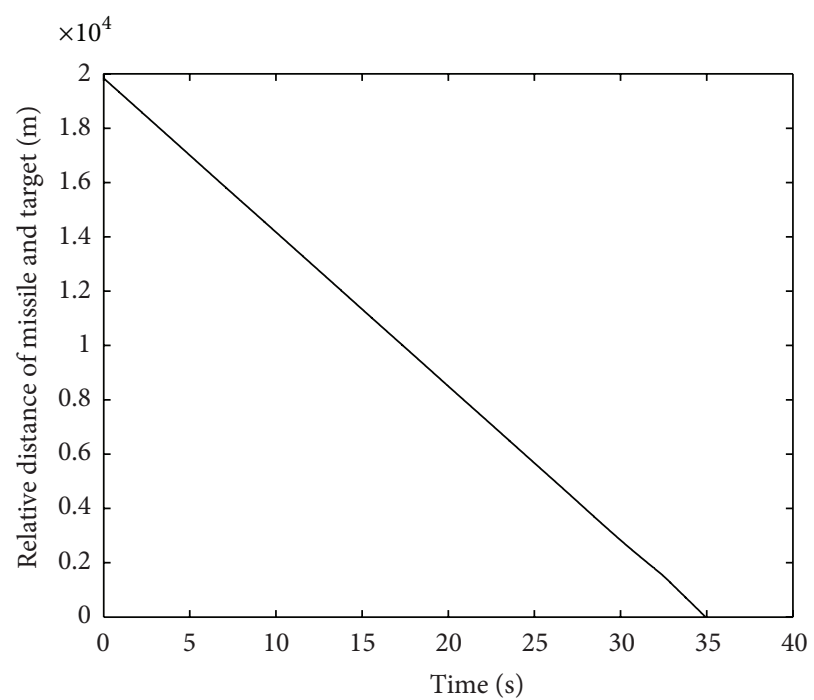

FIgURE 9: Relative distance of missile and target.

and 17, despite the variation of target's absolute speed and its direction, the missile hits the target at $35.05 \mathrm{~s}$ with the impact time error of $0.05 \mathrm{~s}$. Figures 13 and 17 reveal that the missile impacts the target with $0.00476 \mathrm{~m}$ final miss distance. The acceleration of missile shown in Figure 16 guarantees that the LOS angular rate and the rate of time-to-go converge to a small neighborhood of sliding surface as shown in Figures 14 and 15.

Case 3 (multimissile attacks a maneuvering target). This case was performed with the ITGAD applied to a salvo attack to improve the probability of hitting the target. In this simulation three missiles with different conditions are required to impact a maneuvering target at a desired impact 


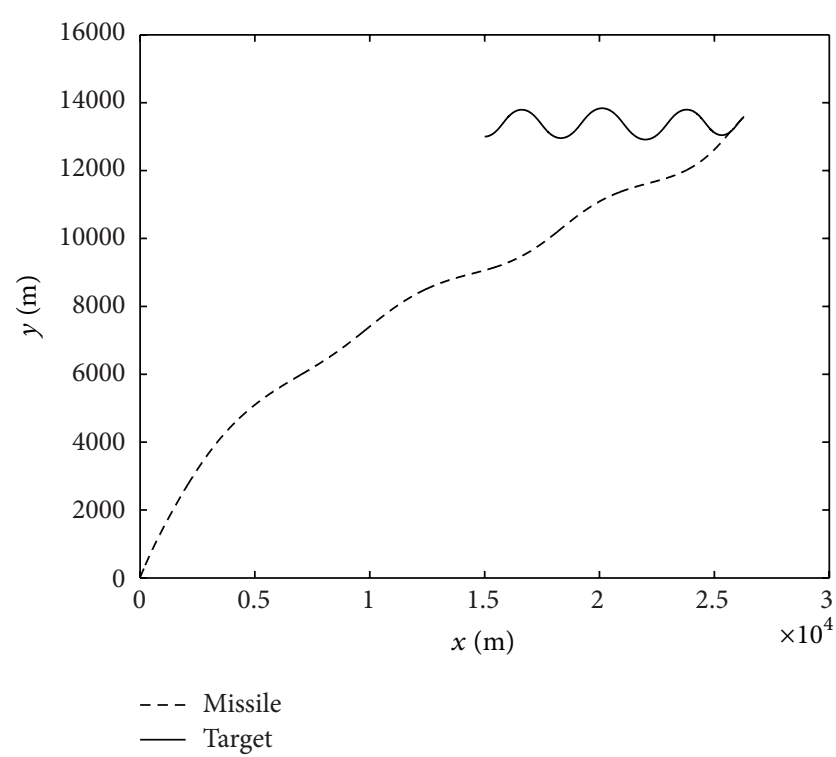

Figure 10: Trajectories of missile and target under FTCG.

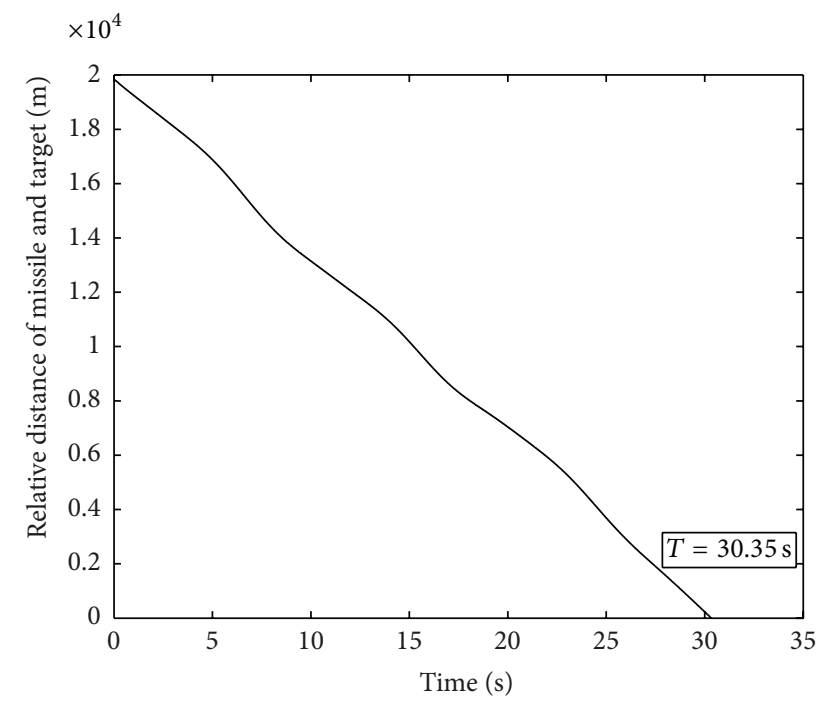

FIgURE 11: Relative distance of missile and target under FTCG.

time. The initial conditions are given in Table 1. The initial velocity and acceleration are the same as Case 1 . The desired impact time for each missile is set to be $35 \mathrm{~s}$. Figure 10 shows the trajectories of the three missiles under FTCG. The impact time under different initial conditions is $27.08 \mathrm{~s}, 30.62 \mathrm{~s}$, and $28.05 \mathrm{~s}$, respectively. So the three missiles impact the target at the different positions as shown in Figure 18. Figure 19 demonstrates that the three missiles under ITGAD impact the target at the same position. The impact time and the final miss distance are shown in Table 2. In this simulation, ITGAD reduced the impact time dispersion within about $0.1 \mathrm{~s}$ around the designated value.

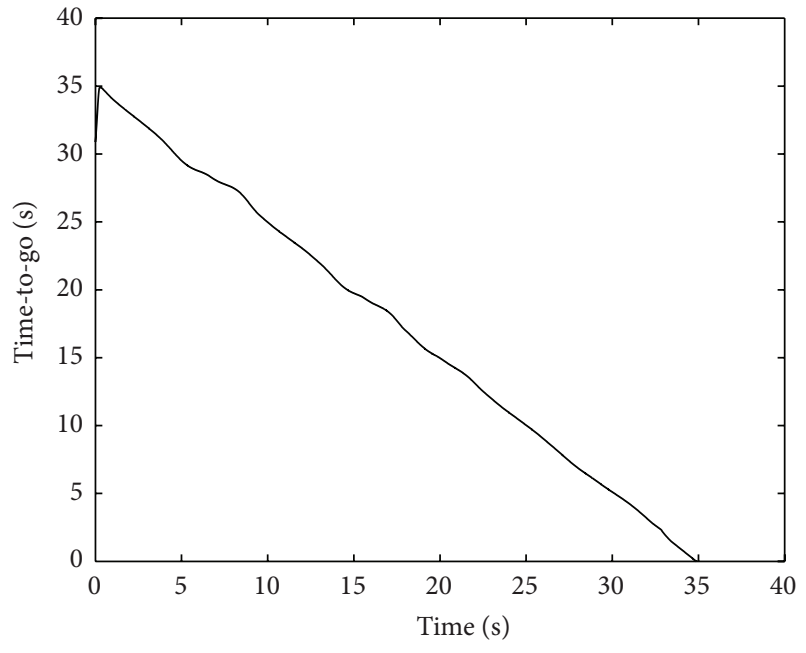

Figure 12: Time-to-go.

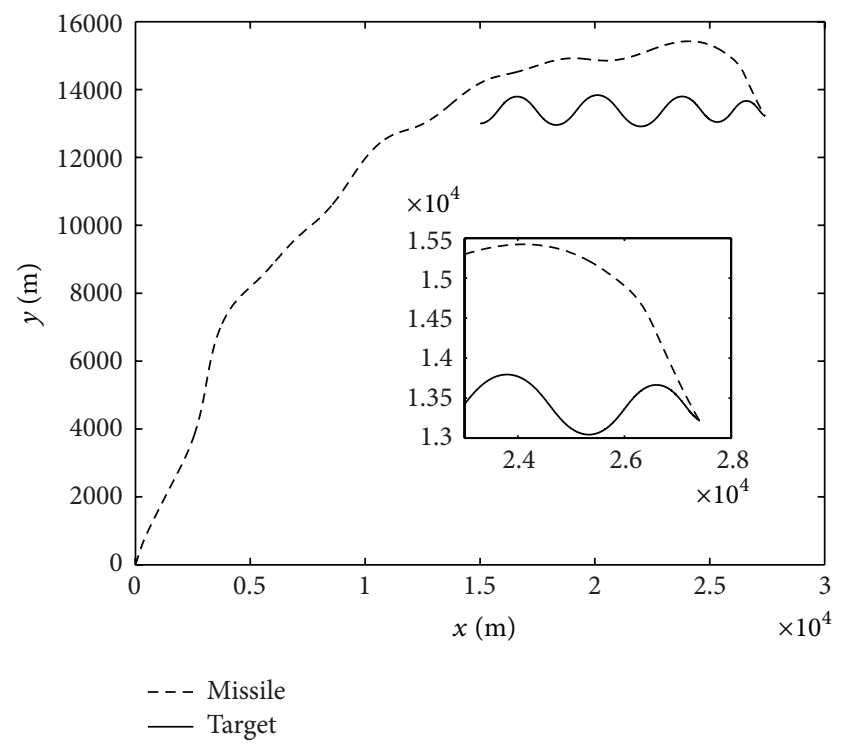

FIGURE 13: Trajectories of missile and target.

TABLE 1: Initial condition of each missile.

\begin{tabular}{lccc}
\hline & $x_{0}(\mathrm{~km})$ & $y_{0}(\mathrm{~km})$ & $\theta_{M 0}(\mathrm{deg})$. \\
\hline Missile 1 & 3 & -3 & 60 \\
Missile 2 & -3 & 5 & 50 \\
Missile 3 & 1 & -1 & 50 \\
\hline
\end{tabular}

TABLE 2: Impact time and final miss distance of each missile.

\begin{tabular}{lccc}
\hline & Missile 1 & Missile 2 & Missile 3 \\
\hline Impact time (s) & 35.07 & 34.98 & 35.04 \\
Final miss distance (m) & 0.0962 & 0.1459 & 0.0301 \\
\hline
\end{tabular}




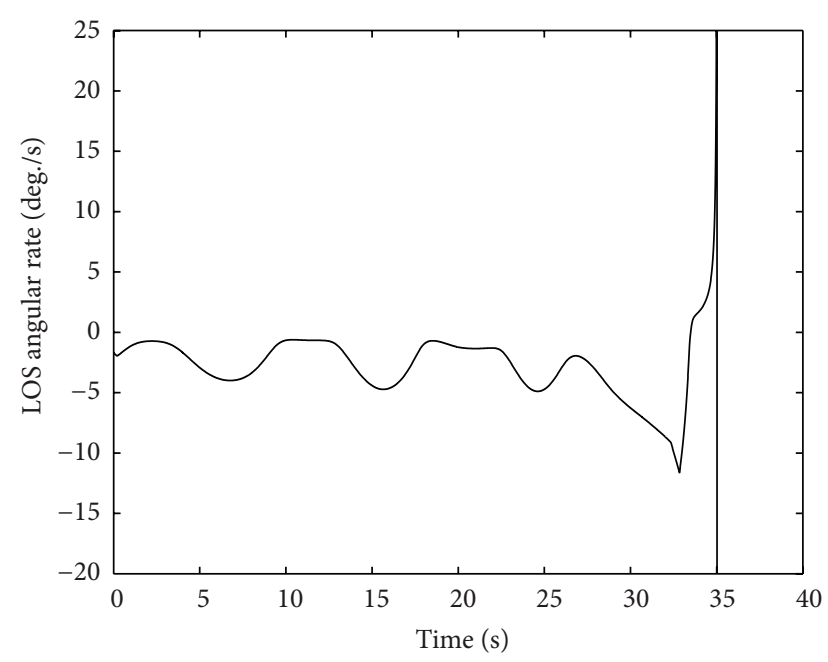

FIGURE 14: LOS angular rate.

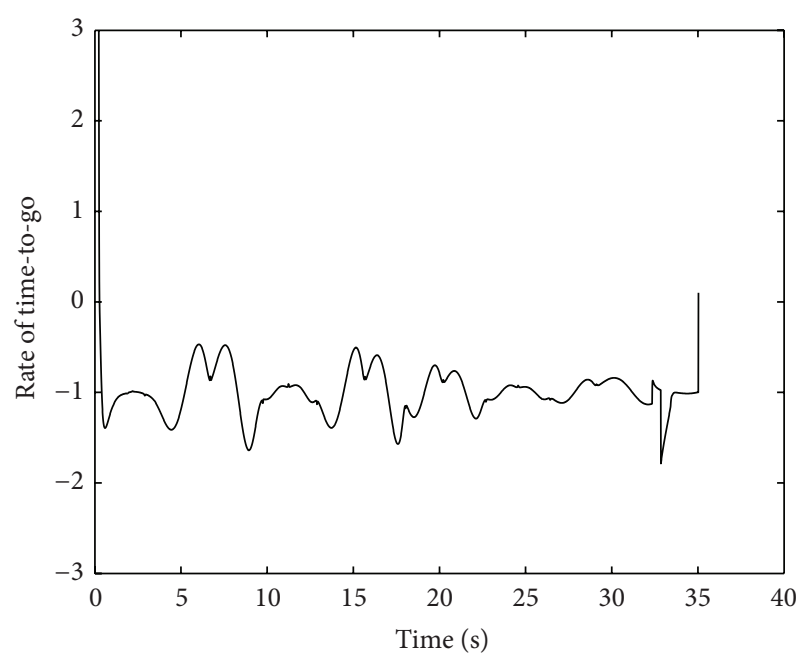

FIGURE 15: Rate of time-to-go.

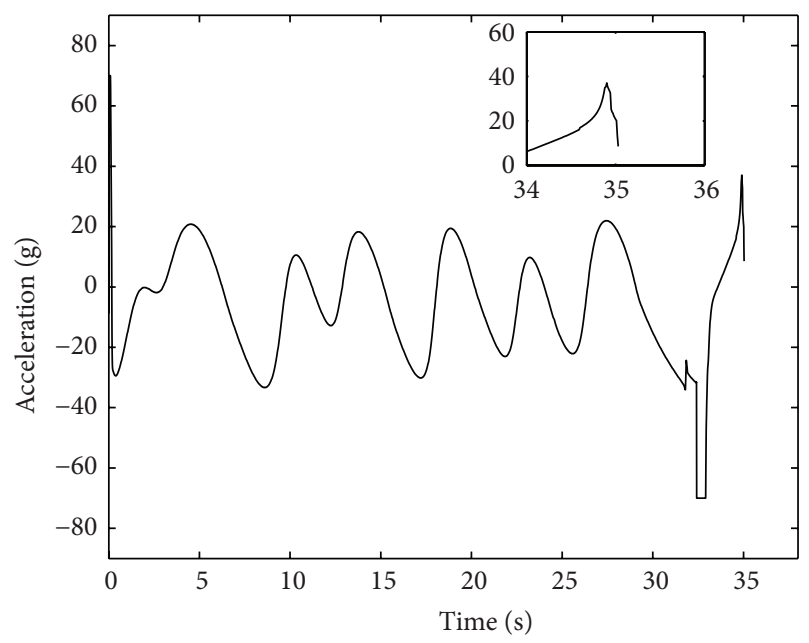

Figure 16: The acceleration of missile.

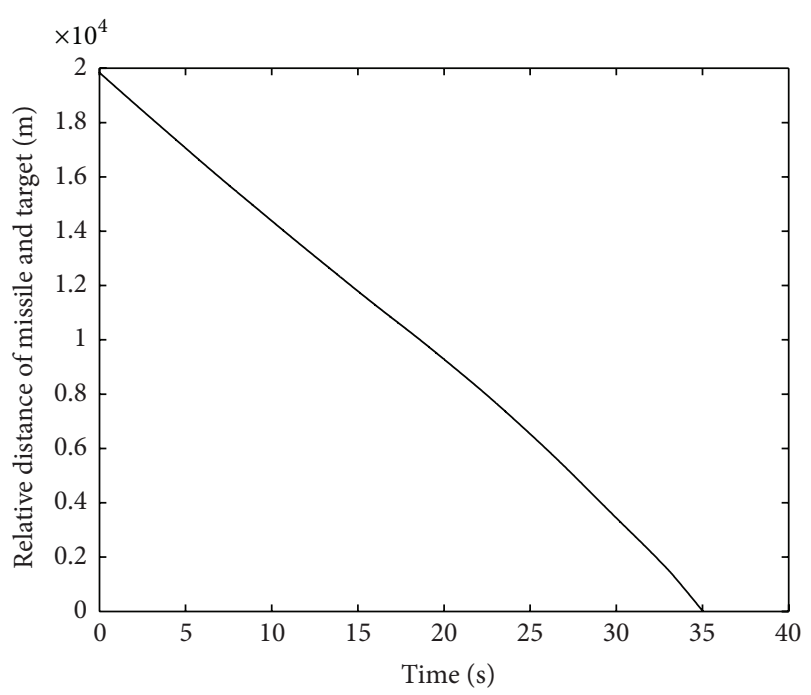

FIgURE 17: Relative distance of missile and target.

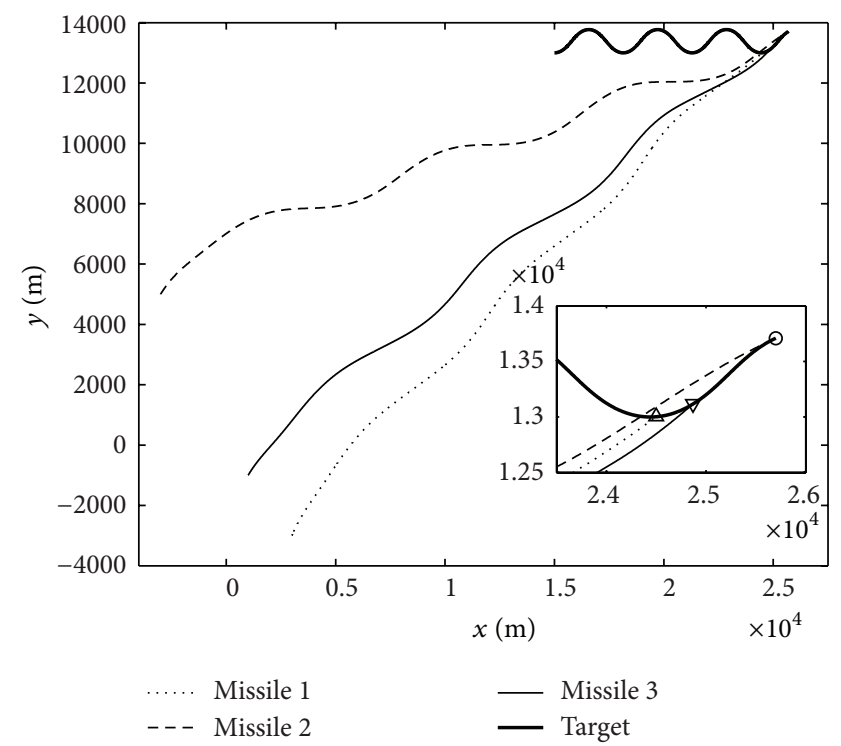

FIGURE 18: Trajectories of missiles and target under FTCG.

\section{Conclusions}

In this paper, to impact a maneuvering target at a desired impact time, an impact time guidance law based on finite time convergence control theory has been designed. In ITGAD, the autopilot dynamics is also taken into consideration to compensate the lag between the expected command and the achieved command. Through the use of ITGAD, the states of guidance system including impact time and LOS angular rate converge to sliding surface in finite time. And the ITGAD achieves the guidance objective taking the target motion as disturbance since the target motion cannot be known in advance. The performance and the feasibility of the ITGAD are demonstrated through several simulations against the maneuvering target. 


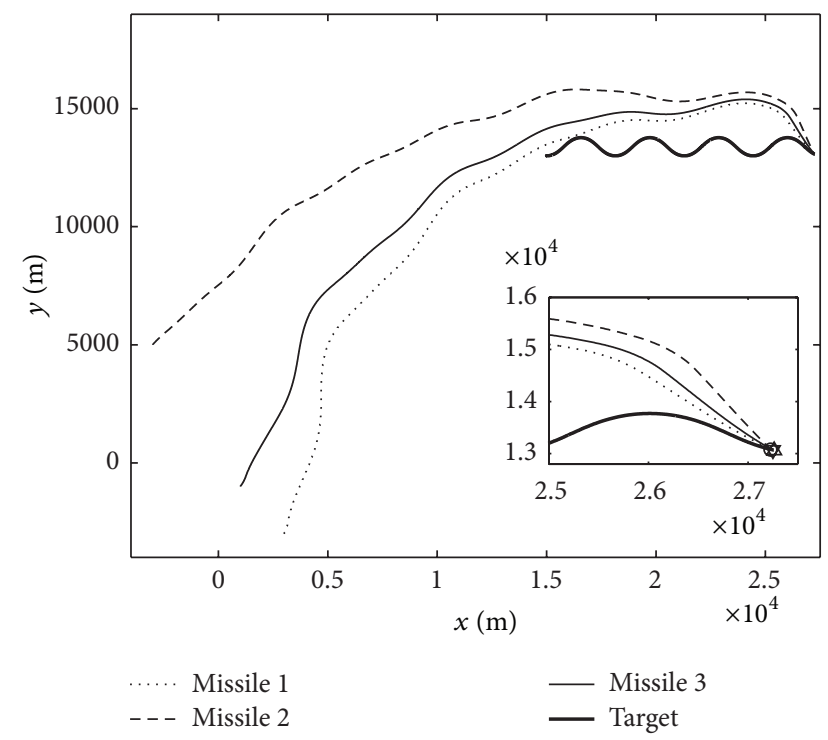

FIGURE 19: Trajectories of missiles and target under ITGAD.

\section{Conflict of Interests}

The authors declare that there is no conflict of interests regarding the publication of this paper.

\section{References}

[1] I.-S. Jeon, J.-I. Lee, and M.-J. Tahk, "Homing guidance law for cooperative attack of multiple missiles," Journal of Guidance, Control, and Dynamics, vol. 33, no. 1, pp. 275-280, 2010.

[2] I.-S. Jeon, J.-I. Lee, and M.-J. Tahk, "Impact-time-control guidance law for anti-ship missiles," IEEE Transactions on Control Systems Technology, vol. 14, no. 2, pp. 260-266, 2006.

[3] J.-I. Lee, I.-S. Jeon, and M.-J. Tahk, "Guidance law to control impact time and angle," IEEE Transactions on Aerospace and Electronic Systems, vol. 43, no. 1, pp. 301-310, 2007.

[4] N. Harl and S. N. Balakrishnan, "Impact time and angle guidance with sliding mode control," IEEE Transactions on Control Systems Technology, vol. 20, no. 6, pp. 1436-1449, 2012.

[5] Y. Zhang, G. Ma, and A. Liu, "Guidance law with impact time and impact angle constraints," Chinese Journal of Aeronautics, vol. 26, no. 4, pp. 960-966, 2013.

[6] X. Sun, R. Zhou, D. Hou, and J. Wu, "Consensus of leaderfollowers system of multi-missile with time-delays and switching topologies," Optik, vol. 125, no. 3, pp. 1202-1208, 2014.

[7] S. Zhao and R. Zhou, "Cooperative guidance for multimissile salvo attack," Chinese Journal of Aeronautics, vol. 21, no. 6, pp. 533-539, 2008.

[8] V. Shaferman and T. Shima, "Cooperative multiple-model adaptive guidance for an aircraft defending missile," Journal of Guidance, Control, and Dynamics, vol. 33, no. 6, pp. 1801-1813, 2010.

[9] D. Zhou, P. Qu, and S. Sun, "A guidance law with terminal impact angle constraint accounting for missile autopilot," Transactions of the ASME, Journal of Dynamic Systems, Measurement and Control, vol. 135, no. 5, Article ID 051009, 2013.

[10] D. Chwa, J. Y. Choi, and S. G. Anavatti, "Observer-based adaptive guidance law considering target uncertainties and control loop dynamics," IEEE Transactions on Control Systems Technology, vol. 14, no. 1, pp. 112-123, 2006.

[11] D. Zhou, P. Qu, and S. Sun, "A guidance law with terminal impact angle constraint accounting for missile autopilot," Journal of Dynamic Systems, Measurement and Control, vol. 135, no. 5, Article ID 051009, 2013.

[12] S. Sun, D. Zhou, and W.-T. Hou, "A guidance law with finite time convergence accounting for autopilot lag," Aerospace Science and Technology, vol. 25, no. 1, pp. 132-137, 2013.

[13] S. S. Moosapour, G. Alizadeh, S. Khanmohammadi, and H. Moosapour, "A novel robust proportional navigation guidance law design for missile considering autopilot dynamic," Transactions of the Institute of Measurement and Control, vol. 35, no. 5, pp. 703-710, 2013.

[14] D. Chwa and J. Y. Choi, "Adaptive nonlinear guidance law considering control loop dynamics," IEEE Transactions on Aerospace and Electronic Systems, vol. 39, no. 4, pp. 1134-1143, 2003.

[15] P. Qu and D. Zhou, "A dimension reduction observer-based guidance law accounting for dynamics of missile autopilot," Proceedings of the Institution of Mechanical Engineers, Part G: Journal of Aerospace Engineering, vol. 227, no. 7, pp. 1114-1121, 2013.

[16] G. L. Li, H. Yan, and H. B. Ji, "A guidance law with finite time convergence considering autopilot dynamics and uncertainties," International Journal of Control, Automation and Systems, vol. 12, no. 5, pp. 1011-1017, 2014.

[17] D. Zhou, S. Sun, and K. L. Teo, "Guidance laws with finite time convergence," Journal of Guidance, Control, and Dynamics, vol. 32, no. 6, pp. 1838-1846, 2009.

[18] S. P. Bhat and D. S. Bernstein, "Finite-time stability of homogeneous systems," in Proceedings of the American Control Conference, vol. 4, pp. 2513-2514, 1997. 


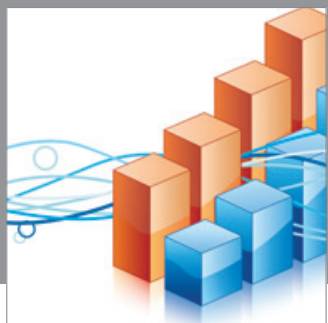

Advances in

Operations Research

mansans

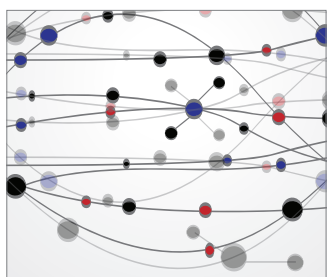

The Scientific World Journal
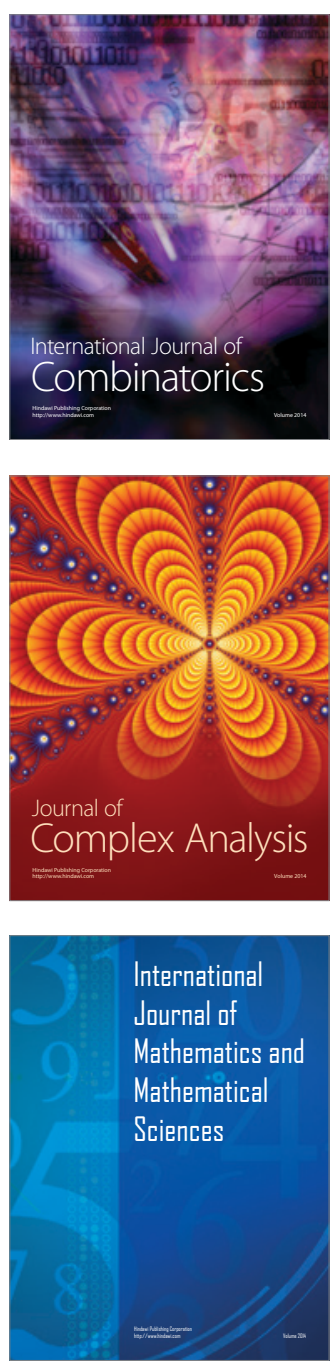
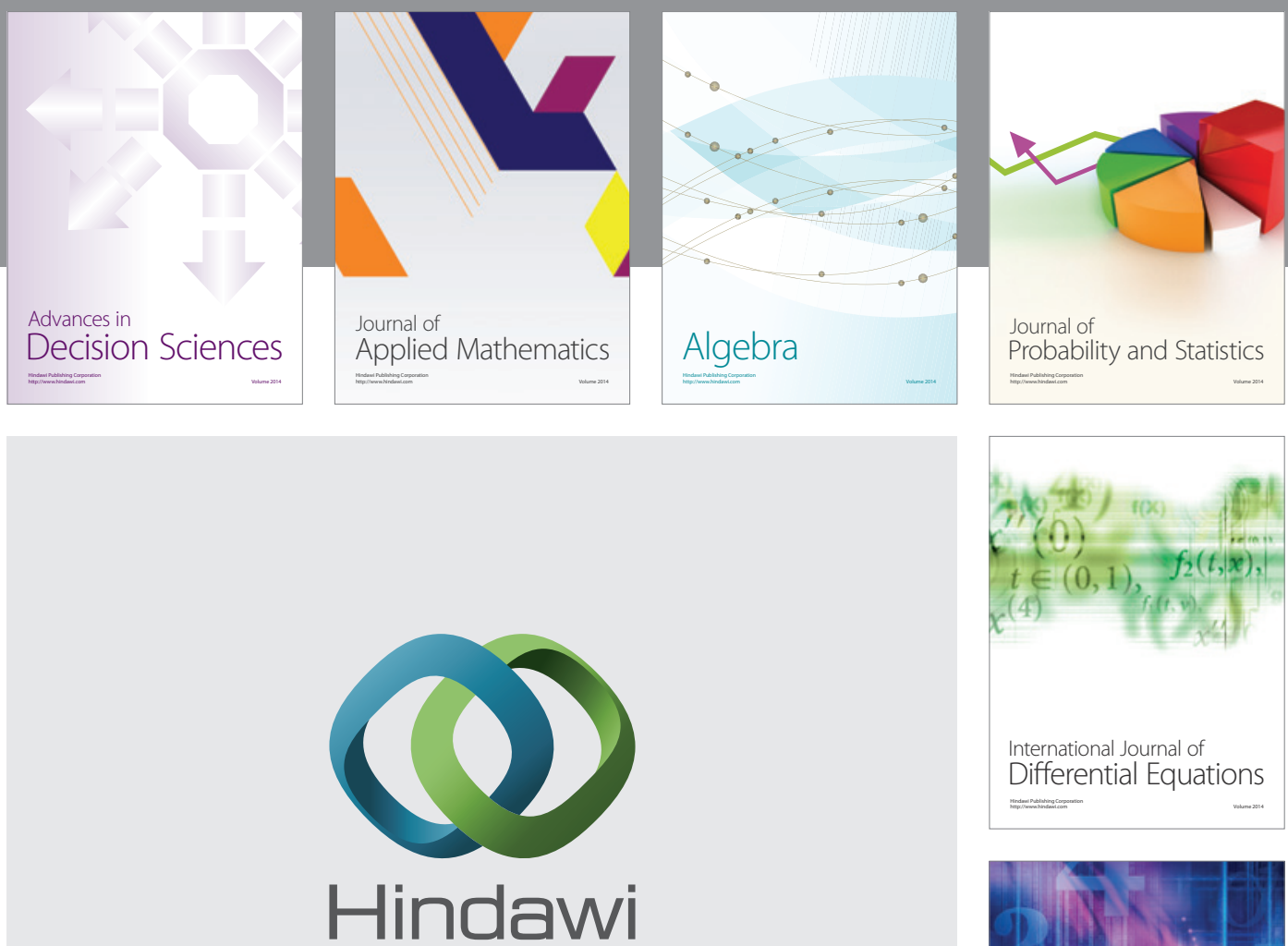

Submit your manuscripts at http://www.hindawi.com
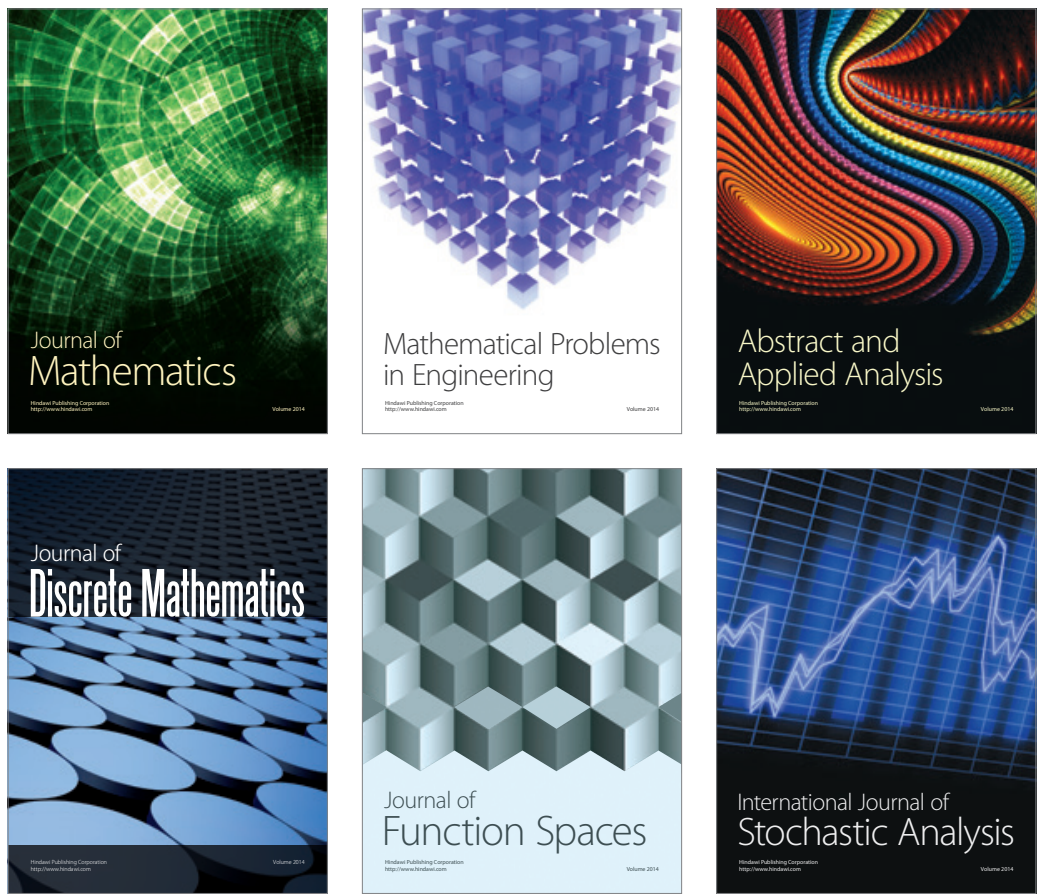

Journal of

Function Spaces

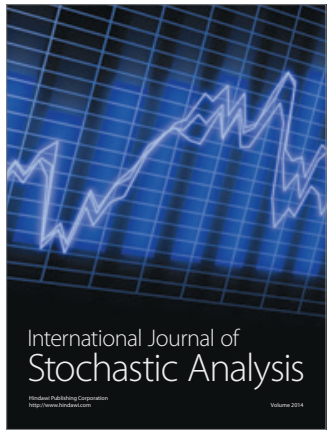

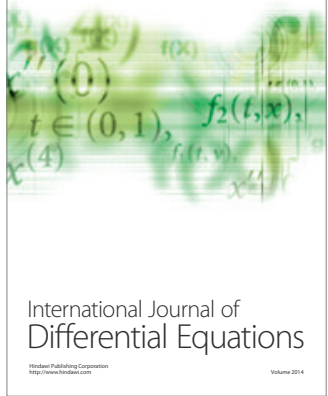
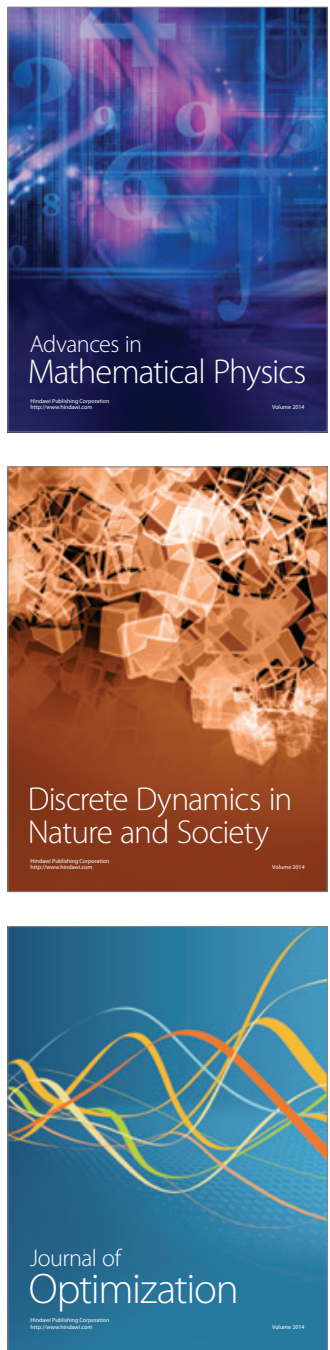